\title{
Study protocol for promoting physical activity among women based on the MAPP process
}

Leila Amiri Farahani ${ }^{1}$, Soroor Parvizy ${ }^{2}$, Mohsen Asadi-Lari ${ }^{3}$, Eesa Mohammadi ${ }^{4}$, Batool Hasanpoor Azghadi ${ }^{1}$ and Ziba Taghizadeh ${ }^{5}$

${ }^{1}$ Department of Reproductive Health and Midwifery, School of Nursing and Midwifery, Iran University of Medical Sciences, Tehran, Islamic Republic of Iran. ${ }^{2}$ Department of Pediatric Nursing, Faculty of Nursing and Midwifery, Iran University of Medical Sciences, Tehran, Islamic Republic of Iran. ${ }^{3}$ Oncopathology Research Centre, IUMS, Tehran, Islamic Republic of Iran. ${ }^{4}$ Department of Nursing, Faculty of Medical Sciences, Tarbiat Modares University, Tehran, Islamic Republic of Iran. ${ }^{5}$ Nursing and Midwifery Care Research Center, Nursing and Midwifery School, Tehran University of Medical Sciences, Tehran, Islamic Republic of Iran (Correspondence to: Z. Taghizadeh: Zibataghizadeh@yahoo.com).

\begin{abstract}
Background: The participation of all stakeholders is necessary when a community-based intervention is designed. For running a practical intervention, it is necessary to have a framework to design the programme while considering all stages of planning, implementation and evaluation.
\end{abstract}

Aims: To describe a study protocol based on the MAPP process (Mobilizing for Action through Planning and Partnerships) for promoting physical activity (PA).

Methods: This protocol is implemented in 6 distinct phases. The goal of the first and second phase is to organize the programme and increase participation, and to determine the vision of the programme, respectively. The third phase provides a comprehensive picture of a community. The fourth and fifth phases identify strategies for the programme. The sixth phase is about the action cycle.

Conclusion: The framework considers all factors on PA improvement and, consequently, results in a culture-based programme for women.

Keywords: Islamic Republic of Iran, MAPP process, methods, physical activity, women

Citation: Amiri Farahani L; Parvizy S; Asadi-Lari M; Mohammadi E; Hasnapoor Azghadi B; Taghizadeh Z. Study protocol for promoting physical activity among women based on the MAPP process. East Mediterr Health J. 2018;24(11):1074-1081. https://doi.org/10.26719/2018.24.11.1074

Received: 21/09/16; accepted: 15/08/17

Copyright (c) World Health Organization (WHO) 2018. Some rights reserved. This work is available under the CC BY-NC-SA 3.0 IGO license (https:// creativecommons.org/licenses/by-nc-sa/3.o/igo).

\section{Introduction}

Despite the numerous health benefits of regular physical activity (PA), physical inactivity is a major health issue in developed and developing countries such as the Islamic Republic of Iran (1). There is strong evidence that physical inactivity increases the risk of chronic conditions such as stroke, cancer, coronary heart disease, type 2 diabetes, obesity and mental health problems (1-3).

According to the World Health Organization (WHO) report (4), globally, around $28 \%$ of men and $34 \%$ of women aged $\geq 15$ years were insufficiently active in 2008. The prevalence of insufficient PA was highest in the WHO Region of the Americas and the Eastern Mediterranean Region, which includes the Islamic Republic of Iran. In all WHO Regions, men were more active than women, with the biggest difference in prevalence between the sexes in the Eastern Mediterranean Region (4). Other studies reported $31.6 \%$ of adult men and $48.6 \%$ of adult women belonged to the low PA category (5). According to the Second Report of Urban Health Equity Assessment and Response Tool (Urban HEART) project in 2011 in Tehran, Islamic Republic of Iran, only $20.5 \%$ of women and $24.3 \%$ of men exercised for at least the minimum time recommended in the PA guidelines (6). These guidelines recommend a minimum of 150 minutes of moderate intensity exercise or 75 minutes of vigorous intensity exercise per week (3).
Although the health benefits of PA are now well established, there is not enough knowledge about the effectiveness of interventions designed for promoting PA at the community level (7). The majority of PA interventions have been delivered at the individual level with the goal of changing personal behaviour (8).

Since individual lifestyles are formed in different social, physical and cultural contexts, when designing a community-based multilevel intervention, it is necessary to include the participation of all stakeholders (9). Community-based interventions may be more effective and successful than traditional and clinic-based programmes (10-12). Community-based interventions consider multilevel approaches on the basis of ecological perspectives and include interventions at different levels such as group, organization, community and policy. These make community-based interventions suitable and practical for health promotion programmes (7, 13). Involvement of community members in planning, implementation and evaluation of community-based interventions means that they can be more effective and sustainable than individual interventions $(14,15)$.

Action research is a community-based approach in which researchers follow the action and results of the study simultaneously (16-18). In this type of study, the researchers cooperate as observers and as agents of change. The researchers gather and analyse the data, 
report the results to specialists, apply changes to the study, and evaluate the effects of any changes (16-19).

WHO is the first organization to initiate communitybased activity for promotion of PA. One of the voluntary global targets is 10\% relative reduction in prevalence of insufficient PA. WHO-proposed policy options include: (1) adoption and implementation of national guidelines; (2) establishment of a multisectorial committee to provide strategic leadership and coordination; (3) development of appropriate partnerships and engagement of all stakeholders, across governments, nongovernmental organizations, and civil society; (4) development of policy measures in cooperation with relevant sectors to promote PA through activities of daily living, including active transport, recreation, leisure and sport; (5) improved provision of quality physical education; (6) actions to support and encourage PA for all initiatives for all ages; (7) promotion of community involvement in implementation of local actions aimed at increasing PA; and (8) conduct of evidence-informed public campaigns through mass media, social media and at the community level to motivate adults about the benefits of PA (20).

Multiple-stage action research takes a long time. It includes problem assessment, action planning, observation, giving and receiving feedback, and problem reassessment that all are carried out with discussion among participants (21). To design the programme, it is necessary to achieve a framework that considers all stages of multiple-stage action research.

The framework utilized for this study is the MAPP process (Mobilizing for Action through Planning and Partnerships). MAPP is a comprehensive, multicomponent, strategic planning model developed as a tool by the National Association of County and City Health Officials (NACCHO) and the Centers for Disease Control and Prevention (CDC) in 2001. The MAPP process plans a health promotion programme by designing a framework. The framework aggregates organizations, groups of people, stakeholders and key informants that are assigned with available resources in the community. Continuous involvement of the community leads to ownership of the process, and ownership by the community increases the sustainability and validity of health promotion efforts. The MAPP process prioritizes public health issues in the community, identifies available resources, and designs appropriate strategies in community context $(22,23)$. These are the goals in action research.

This paper describes a study protocol based on the MAPP process for promoting PA among women aged 18-65 years. The study protocol is a part of a $\mathrm{PhD}$ thesis (24). The overarching goal of this project is to develop a programme with community-based interventions for promoting PA among Iranian women.

\section{Methods}

This is a multiphase, mixed-method action research method based on the MAPP process, which includes the 6 phases shown in Figure 1.
The first phase, "Organizing success and partnership development" is part of the planning phase. This phase identifies who should be involved in the process and how the partnership will be approached in order to organize the process.

The second phase, "Visioning", is a collaborative and creative approach that leads to a shared community vision and common values.

The third phase, "Four assessments" brings in a comprehensive picture of a community by using both qualitative and quantitative methods. Most planning processes look only at quantitative statistics and anecdotal data. The four assessments consist of the following. (1) Community health status assessment to provide quantitative data on a broad array of health indicators, such as behavioural risk factors, and other measures that reflect a broad definition of health. (2) Forces of change assessment provides an analysis of positive and negative external forces that affect promotion and protection of public health. (3) Community themes and strengths assessment provides qualitative information on how communities perceive their health and quality of life concerns, as well as their knowledge of community resources and assets. (4) Local public health system assessment is a comprehensive assessment of all organizations and entities that contribute to public health.

The Fourth phase, "Identify strategic issues", uses information collected in the Four assessments phase to determine which strategic issues should be addressed by a community in order to reach its vision. It is necessary that this phase answers the following questions. What are the factors identified in the assessments that must be addressed in order to achieve the vision? What are the consequences of not addressing them?

The fifth phase, "Formulate goals and strategies", assigns goals to each of the strategic issues identified in the previous phase. Many communities create a community health improvement plan at the end of this phase. This phase answers the following questions. What do we want to achieve by addressing this strategic issue? How do we want to achieve it? What action is needed?

The sixth phase, "Action cycle", includes planning, implementation and evaluation of a community-based strategic plan. Participants contribute to the action by determining what will be done, who will do it, and how it will be done, in the implementation by carrying out the activities identified at the planning stage, and in the evaluation by determining what will be accomplished.

\section{First phase: Organizing success and partnership development}

A wide range of collaborators is selected to support the programme and each person can bring resources and capital, and the method of supplying them is identified. To achieve the objectives of this phase, the following people should be involved in the process: core research committee; steering committee composed of policy-makers 


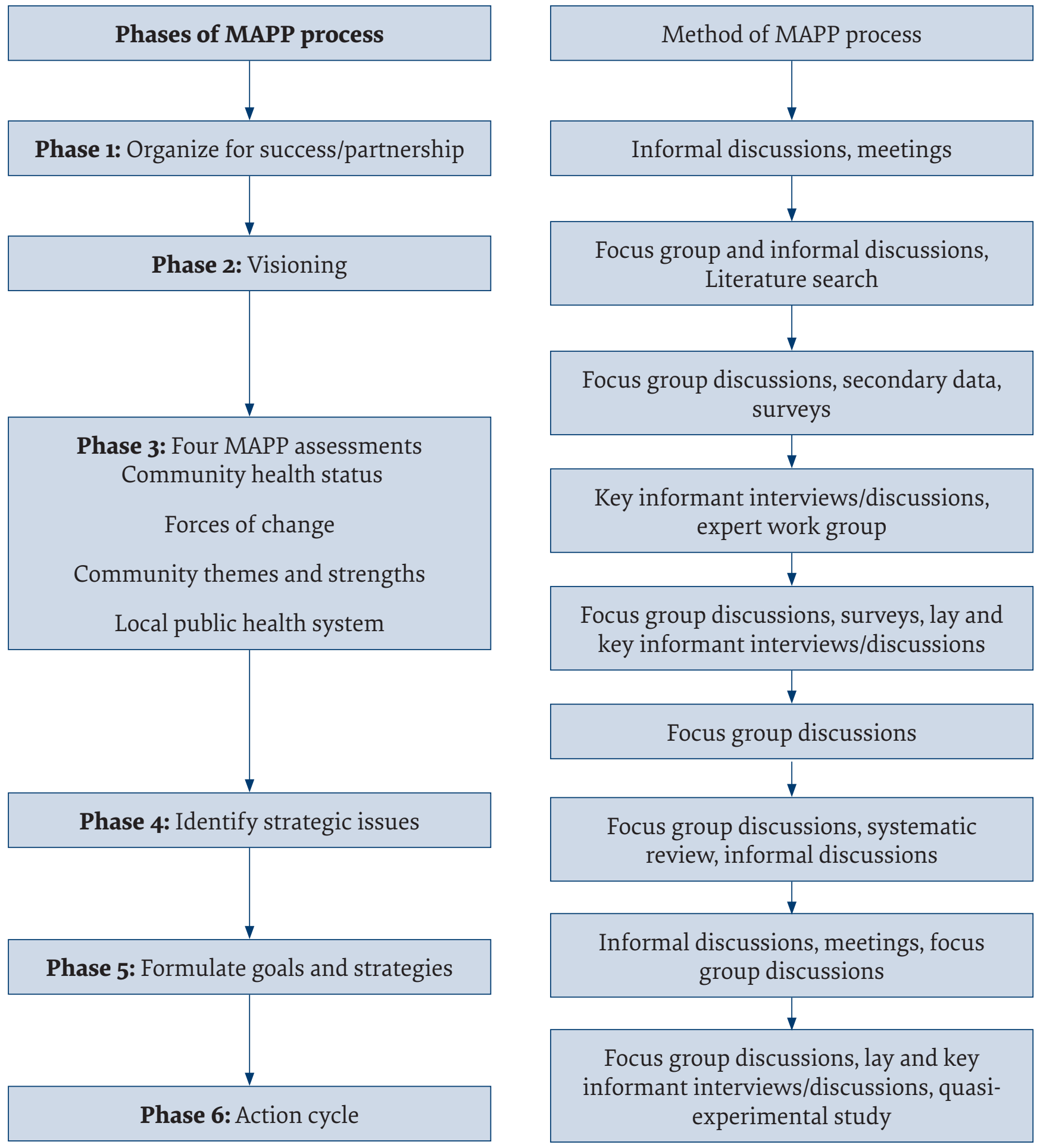

Figure 1 Flow chart of different methods used in the six phases of the MAPP process

and officials from within or outwith Khaneh Salamat'; and research population members. Focus group discussions (FGDs) are held between participants and experts involved in the programme. They talk about their perception of the problem of insufficient PA and the necessity to promote it, expertise, ability to overcome obstacles, and funds that can be devoted to the programme.

\section{Second phase: Visioning}

The vision can help to focus and set goals and paths in the MAPP process. MAPP creates partnerships to achieve that vision in the future. The core research committee and research population members organize FGDs to identify the vision of the PA promotion programme. The

Khaneh Salamat is a community centre that provides preventive care and health promotion programmes. 
identified vision needs to be in agreement with the vision set by the steering committee.

\section{Third phase: Four assessments}

The Four assessment phase evaluates community health status, the forces of change, community themes and strengths, and local public health systems. The assessments are a scan of the internal and external environment of the PA programme to identify strengths and weaknesses that are internal to the programme and opportunities and threats external to the programme in the environment in which it operates. It is a useful tool for reducing a large amount of data into a more manageable profile for the health programme, and it provides a framework for identifying the issues that affect the strategic plan. The assessments are as follows.

\section{Community health status assessment}

This part has 2 sections: one to assess prevalence of PA and another to reach to stakeholders' consensus about the importance of PA improvement. In the first section, prevalence of PA in women is obtained from available statistical evidence at the national, regional, state, district and zone level; in this case, Zone 2 of District 2 in Tehran. This is located in the northwest of the city and according to self-perceptions, the residents are mediocre in socioeconomic status. To establish prevalence of sufficient PA, a cross-sectional survey is conducted among women aged 18-65 years residing in Khoramrudi neighbourhood in the Second Municipal District of Tehran. The sample size of the current study is 300 , according to the studies conducted on PA for the Urban HEART project (6), with $\mathrm{P}=$ $23 \%, \mathrm{~d}=0.05 \%_{-}=0.05$ and $\mathrm{Z}=1.96$ and ${ }_{-}=0.2$. According to the Second Report (2011) of the Urban HEART project in Tehran, every neighbourhood of 22 municipal districts of Tehran is divided into several blocks. We use available information about the blocks located in Khoramroudi neighbourhood. Khoramroudi has numerous blocks; however, we only select some blocks using a systematic sampling method in which women aged 18-65 years are interviewed. If a woman declines to take part, her neighbour will be invited to participate and complete the questionnaire. In the second section, the core research committee, steering committee and research population members discuss the importance of PA and it is necessary to reach consensus.

\section{Forces of change assessment}

The Forces of change assessment focuses on identifying forces such as legislation, technology and other impending changes that affect the context in which the community and its public health system operate. The core research committee collects data about barriers and facilitators of PA for written and/or verbal documents via individual interviews and/or FGDs with research population members and managers. It is necessary to ask all the stakeholders to share their experiences about preventive forces of change that are the facilitators inside the organization and opportunities outside the organization, and positive forces of change that are the barriers inside the organization and threats outside the organization. In addition to qualitative data, quantitative data are collected using the Exercise Benefit and Barrier Scale (EBBS). Barriers and facilitators of PA are identified thorough the cross-sectional study defined in the community health status assessment section.

Local public health system assessment and community themes and strengths assessment

All assessments focus on the organizations and entities that contribute to public health and provide a deep understanding of the PA status in Khoramrudi neighbourhood, and what assets do we have that can be used to improve it. These assessments evaluate community themes and strengths and the local public health system through FGDs among the core research committee, steering committee and research population members.

\section{Fourth phase: Identify strategic issues}

The fourth phase identifies strategic issues of the PA programme using information gathered from the Four assessments phase. Strategic issues of a community must be addressed to achieve the vision of the PA programme. This phase is planned using data collected in previous phases and shows important and changeable strategies for PA enhancement. The best and most suitable strategies are identified in this phase by a systematic review and FGDs among the core research committee, steering committee and research population members.

\section{Fifth phase: Formulate goals and strategies}

The fifth phase involves specifying goals for each of the strategic issues identified in the previous phase. Many communities create a community health improvement plan at the end of this phase. Potential barriers, required actions, available resources, and a time plan must be considered in this phase.

\section{Sixth phase: Action cycle}

The Action cycle, includes planning, implementation and evaluation of the community strategic plan. Each strategy is implemented and then evaluated by quantitative and qualitative methods. The quantitative method is based on a quasi-experimental study in which the assessment is carried out before interventions and 1 and 3 months after. To improve the quality of the study and design a more inclusive programme, the qualitative assessments of the study are conducted during the programme, focus groups, individual interviews, and through feedback from participants throughout and after the study. These assessments are performed at 1-month intervals throughout and after the study.

\section{Data collection}

\section{Scales and quantitative data collection}

1. The international PA questionnaire (IPAQ) was designed to measure PA level within the last 7 days. The IPAQ is an interview-administered instrument and contains 4 domains: work, transportation, domestic chores and gardening, and leisure time (25, 
26). The validity and reliability of the questionnaire in the Islamic Republic of Iran was measured by Moghaddam et al. through the forward-backward translation method (27). The validity of IPAQ was confirmed by the face, content and constructs validity. For the reliability of IPAQ, Cronbach's $\alpha$ coefficient was used to calculate internal consistency and the Spearman-Brown coefficient was used to assess the stability over time. In terms of internal consistency, Cronbach's $\alpha$ of the questionnaire was 0.7 and the Spearman correlation coefficient of IPAQ was 0.9 in test-retest reliability (27). In the current study, the reliability of IPAQ will be assessed from internal consistency and stability.

2. The EBBS was originally designed by Sechrist et al. as a general and self-administered scale to evaluate barriers and facilitators of PA (28). It consists of 43 items; 14 barriers scales that are composed of 4 subscales of exercise milieu, time expenditure, physical exertion and family discouragement; and 29 benefits scales that are composed of 5 subscales of life enhancement, physical performance, psychological outlook, social interaction and preventative health (28). EBBS was translated in the Islamic Republic of Iran by Farahani et al., using the forward-backward translation method (29). It has also been adapted to the Persian culture and its validity has been confirmed by the face, content and constructs validity. For the reliability of EBBS, Cronbach's $\alpha$ coefficient was used to calculate internal consistency and the Spearman-Brown coefficient was used to assess the stability over time. Cronbach's $\alpha$ coefficient for the total scale and the subscales of benefits and barriers was 0.927, 0.94 and 0.82 and the Spearman-Brown coefficient was 0.76 $(\mathrm{P}=0.004), 0.79(\mathrm{P}=0.046)$ and $0.74(\mathrm{P}=0.008)$ for the total scale, benefits and barriers subscales, respectively (29).

3. The demographic characteristics questionnaire was designed by a research team while considering the following factors: age, ethnicity, education level, occupational status, mother, father and spouse if married, marital status, family size and sufficiency of income.

\section{Qualitative data collection}

Data are collected through FGDs and individual indepth interviews, if required. The FGDs are conducted in Khaneh Salamat and individual interviews are held in places that are convenient for women. The research team reviews the interview questions before conducting FGDs and interviews, and practices ways to help gain valid data. Data are recorded during FGDs and interviews by a tape recorder. Decisions about the number of participants are taken based on data saturation.

\section{Data analysis}

\section{Quantitative data analysis}

Data are analysed using SPSS version 20 through descriptive and inferential statistical methods. Basic descriptive statistics including the mean, standard deviation and frequency are calculated. Statistical tests such as the $\chi^{2}$ test are used to estimate prevalence of PA. Structural equation modelling analysis is used to identify the most important constructs that determine the priorities among benefits and barriers constructs.

\section{Qualitative data analysis}

Qualitative data are analysed using a theme development procedure. Data management is conducted using MAXQDA version 10. Audio interview files are transcribed. Then, researchers examine the content and extract the face and latent themes. Each transcribed word or expression is considered as an individual unit of analysis. Further scrutiny of transcripts and accompanied interpretative notes may contribute to recognition of initial relationships among the concepts extracted from the expressions. Collected notes and codes also help formation of themes. As interviews progress and relationships among the themes emerge, it will be possible to recognize patterns and the main concepts. Moreover, the constant comparison method is used during the research.

The trustworthiness of qualitative studies is based on Guba's criteria (30). Credibility is established through prolonged engagement with participants and extended immersion. Member checking and peer reviewing are done to verify the findings. Triangulation of data collection methods is done using field notes and diaries to collect data. Transferability is facilitated by purposive sampling of women who have experienced regular and irregular PA. Detailed description of the findings and reviewing the literature when interpreting the data are done to support the study findings. An audit trail is conducted to assure confirmability.

\section{Ethical considerations}

In the study phases, it is necessary for participants to give written informed consent. The Ethics Committee of Tehran University of Medical Sciences approved the protocol of this study (code number: 92-02-28-23311) before the collection of samples.

\section{Discussion}

The current action research is designed to provide a community-based programme for promoting PA among women in Khoramrudi neighbourhood, Tehran. Promoting PA helps countries to reach the CDC recommendation of a minimum of 150 minutes of moderate intensity exercise or 75 minutes of vigorous intensity exercise per week. The present study provides information and robust data to plan, implement and evaluate a PA programme thorough a culturally sensitive approach. The collection of quantitative and qualitative data facilitates a better understanding of research goals.

This study also provides some insights about the PA behaviour that need to be considered if effective strategies and intervention programmes are to be designed to promote PA, and subsequently, the health of families in the Islamic Republic of Iran and those 
of other women who may have similar beliefs and practice that need to be dealt with effectively. The findings of the study can help to identify communitybased strategies for promoting PA among women in Khoramrudi neighbourhood. Follow-up is done at the end of the programme in order to assess the shortterm effectiveness of the programme. Evaluation of the results determines the support that is necessary for designing programmes that are accessible, affordable and effective in promoting PA and health among women in Khoramrudi neighbourhood.

\section{Conclusion}

It is believed that the current action research can fill the gaps in the current literature and provide new insights about urban PA. The study uses innovative designs to evaluate interventions and develop collaboration between researchers and practitioners for evaluating experiments. Therefore, the results of this study contribute to the body of evidence about community-level interventions, and can be useful for researchers and practitioners for future evaluation of complex public health interventions. If the intervention proves itself as a successful method for improving PA in a population, this type of intervention could be disseminated in similar contexts.

\section{Acknowledgements}

This study was funded and supported by Tehran University of Medical Sciences (grant no. 92-02-28-23311). The authors would like to express their gratitude to Kayla J. Power for her valuable and kind assistance with English language editing of the article.

Funding: None.

Competing interests: None declared.

\section{Protocole d'étude fondé sur le processus MAPP visant à promouvoir l'activité physique chez les femmes, République islamique d'Iran \\ Résumé}

Contexte: La participation de toutes les parties prenantes est nécessaire durant l'élaboration des interventions communautaires. Pour mettre en œuvre une intervention pratique, il faut disposer d'un cadre afin de concevoir le programme et de prendre en compte toutes les étapes de la planification, de la mise en œuvre et de l'évaluation.

Objectifs : La présente étude visait à décrire un protocole d'étude fondé sur le processus MAPP (Mobilizing for Action through Planning and Partnerships) et ayant pour but de promouvoir l'activité physique.

Méthodes : Le protocole est mis en œuvre en six phases distinctes. La première phase vise à organiser le programme et à accroître la participation, tandis que la deuxième a pour objectif de déterminer la vision du programme. La troisième phase présente un portrait complet d'une communauté. Les quatrième et cinquième phases établissent des stratégies pour le programme. La sixième phase concerne le cycle d'action.

Conclusion : Le cadre considère tous les facteurs qui influent sur l'amélioration de l'activité physique et permet par conséquent de concevoir un programme pour les femmes qui s'appuie sur la culture locale.

$$
\begin{aligned}
& \text { بروتو كول دراسة لتعزيز النشاط البدني بين السيدات استنادًا إلى عملية استنهاض الفمم لملمارسة النشاط من خلال } \\
& \text { التخطيط والشر اكات (MAPP) } \\
& \text { ليلى فراهاني، سُرور برويزى، محسن أسدي -لاري، عيسى محمدي، بتول حسن بور ازقدى، زيبا تقي زادة } \\
& \text { الخالاصة }
\end{aligned}
$$

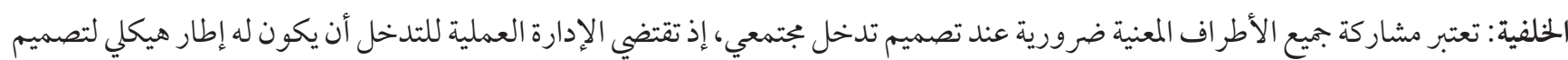

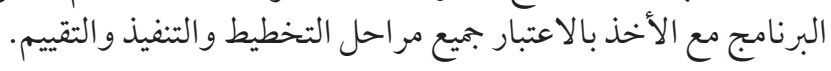

$$
\begin{aligned}
& \text { الأهداف: تهدف الدراسة إلى وصف بروتوكول للدراسة يستند إلى عملية استنهاض الهمم لملمارسة النشاط من خلال التخطيط والشراكات } \\
& \text { (MAPP) }
\end{aligned}
$$

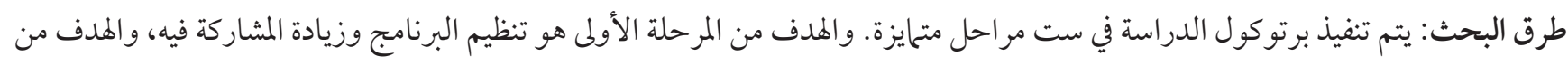

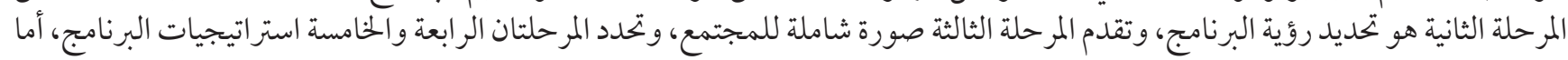

$$
\begin{aligned}
& \text { المرحلة السادسة فتتعلق بدورة العمل. } \\
& \text { الاستنتاجات: يأخذ الإطار الهيكلي في الحسبان جميع العوامل التي تتعلق بتحسين النشاط البدني فيؤدي بالتالي إلى برنامج خصصص للنساء يستند إلى } \\
& \text { الثقافة السائدة. }
\end{aligned}
$$




\section{References}

1. Lee DC, Artero EG, Sui X, Blair SN. Review: Mortality trends in the general population: the importance of cardiorespiratory fitness. J Psychopharmacol. 2010 Nov;24(4_suppl):27-35. https://doi.org/ 0.1177/1359786810382057 PMID:20923918

2. Start active, stay active: a report on physical activity from the four home countries' Chief Medical Officers. London: Department of Health; 2011.

3. Physical Activity Guidelines Advisory Committee. Physical activity guidelines advisory committee report. Washington (DC): U.S. Department of Health and Human Services; 2008 (https://health.gov/paguidelines/report/pdf/CommitteeReport.pdf, accessed 8 March 2018).

4. Global strategy on diet, physical activity and health: a framework to monitor and evaluate implementation. Geneva: World Health Organization; 2006

5. Esteghamati A, Khalilzadeh O, Rashidi A, Kamgar M, Meysamie A, Abbasi M. Physical activity in Iran: results of the third national surveillance of risk factors of non-communicable diseases (SuRFNCD-2007). J Phys Act Health. 2011 Jan;8(1):27-35. https://doi. org/10.1123/jpah.8.1.27 PMID:21297182

6. Asadi-Lari M, Vaez-Mahdavi MR. An overview on Urban-HEART Tehran experience. World Health Organization.

7. Foster C, Hillsdon M, Thorogood M. Interventions for promoting physical activity. Cochrane Database Syst Rev. 2005. Jan 25;(1): CDo03180. https://doi.org/10.1002/14651858.CD003180.pub2 PMID:15674903

8. House of Lords Science and Technology Select Committee. Behaviour change. London: House of Lords; 2011.

9. Trost SG, Owen N, Bauman AE, Sallis JF, Brown W. Correlates of adults' participation in physical activity: review and update. Med Sci Sports Exerc. 2002 Dec;34(12):1996-2001. https://doi.org/10.1097/00005768-200212000-00020 PMID:12471307

10. Stokols D. Establishing and maintaining healthy environments. Toward a social ecology of health promotion. Am Psychol. 1992 Jan;47(1):6-22. https://doi.org/10.1037/0003-066X.47.1.6 PMID:1539925

11. McKinlay JB. The new public health approach to improving physical activity and autonomy in older populations. In: Heikkinen E, Kuusinen J, Ruoppila I, editors. Preparation for aging. Boston: Springer; 1995:87-103.

12. Tsai AC, Morton SC, Mangione CM, Keeler EB. A meta-analysis of interventions to improve care for chronic illnesses. Am J Manag Care. 2005 Aug;11(8):478-88. PMID:16095434

13. Bopp M, Fallon E. Community-based interventions to promote increased physical activity: a primer. Appl Health Econ Health Policy. 2008;6(4):173-87. https://doi.org/10.1007/BF03256132 PMID:19382818

14. Harding AH, Griffin SJ, Wareham NJ. Population impact of strategies for identifying groups at high risk of type 2 diabetes. Prev Med. 2006 May;42(5):364-8. https://doi.org/10.1016/j.ypmed.2006.01.013 PMID:16504278

15. Guttmacher S, Kelly PJ, Ruiz-Janecko Y. Community-based health interventions. San Francisco: Jossey-Bass; 2010.

16. Nieswiadomy RM. Foundations of nursing research. Stamford, CT: Appleton \& Lange; 1998.

17. Speziale HS, Streubert HJ, Carpenter DR. Qualitative research in nursing: advancing the humanistic imperative. Philadelphia: Lippincott Williams \& Wilkins; 2011.

18. Dempsey PA, Dempsey AD. Using nursing research: process, critical evaluation, and utilization. Philadelphia: Lippincott Williams \& Wilkins; 2000.

19. Pilemalm S, Timpka T. Third generation participatory design in health informatics-making user participation applicable to large-scale information system projects. J Biomed Inform. 2008 Apr;41(2):327-39. https://doi.org/10.1016/j.jbi.2007.09.004 PMID:17981514

20. Earl-Slater A. The superiority of action research? Br J Clin Governance. 2002;7(2):132-5. https://doi.org/10.1108/14664100210427633

21. Global action plan for the prevention and control of non-communicable diseases 2013-2020. Geneva: World Health Organization; 2013 (http://apps.who.int/iris/bitstream/10665/94384/1/9789241506236_eng.pdf?ua=1, accessed 8 March 2018).

22. National Association of County and City Health Officials (NACCHO). Mobilizing for Action through Planning and Partnership. Achieving Healthier Communities through MAPP, A user's handbook. http://www.naccho.org/topics/infrastructure/mapp/upload/MAPP_Handbook_fnl.pdf

23. Fact sheet: mobilizing for action through planning and partnerships: a community approach to health improvement. Washington, DC: National Association of County and City Health Officials; 2008 (https://www.naccho.org/programs/public-health-infrastructure/performance-improvement/community-health-assessment/mapp, accessed 8 March 2018)

24. Farahani LA. Improving PA among women: a mixed-method action research in Iran [thesis]. Tehran University of Medical Sciences; 2015.

25. IPAQ. (2005). Guidelines for Data Processing and Analysis of the International Physical Activity Questionnaire (IPAQ) - short and long forms. November 2005.

26. Craig CL, Marshall AL, Sjöström M, Bauman AE, Booth ML, Ainsworth BE, et al. International Physical Activity Questionnaire: 12-country reliability and validity. Med Sci Spor Exerc. 2003 Aug;35(8):1381-90. https://doi.org/10.1249/01.MSS.0000078924.61453. FB PMID:12900694 
27. Baghiani Moghaddam MH, Bakhtari Aghdam F, Asghari Jafarabadi M, Allahverdipour H, Dabagh Nikookheslat S, Safarpour S. The Iranian Version of International Physical Activity Questionnaire (IPAQ) in Iran: Content and Construct Validity, Factor Structure, Internal Consistency and Stability. World Appl Sci J. 2012;18(8):1073-80.

28. Sechrist KR, Walker SN, Pender NJ. Development and psychometric evaluation of the exercise benefits/barriers scale. Res Nurs Health. 1987 Dec;10(6):357-65. https://doi.org/10.1002/nur.4770100603 PMID:3423307

29. Amiri Farahani L, Parvizy S, Mohammadi E, Asadi-Lari M, Kazemnejad A, Hasanpoor-Azgahdy SB, Taghizadeh Z. The Psychometric Properties of Exercise Benefits/Barriers Scale among Women. Electronic Physician journal 2017.

30. Lincoln YS, Guba EG. Naturalistic inquiry. Thousand Oaks, CA: Sage; 1985 